\title{
Enterotoxemia em caprinos no Rio Grande do Sul ${ }^{1}$
}

\author{
Edson M. Colodel ${ }^{2}$, David Driemeier ${ }^{3}$, Milene Schmitz ${ }^{3}$, Marlise Germer ${ }^{3}$, Ricardo A. \\ P. Nascimento ${ }^{4}$, Ronnie A. Assis ${ }^{5}$, Francisco C.F. Lobato ${ }^{5}$ e Francisco A. Uzal ${ }^{6}$
}

\begin{abstract}
Colodel E.M., Driemeier D., Schmitz M., Germer M., Nascimento R.A.P., Assis R.A., Lobato F.C.F. \& Uzal F.A. 2003. [Caprine enterotoxaemia in Rio Grande do Sul, Brazil.] Enterotoxemia em caprinos no Rio Grande do Sul. Pesquisa Veterinária Brasileira 23(4):173-178. Setor de Patologia Veterinária, Depto Patologia Clínica Veterinária, Faculdade de Veterinária, Universidade Federal do Rio Grande do Sul, Av. Bento Gonçalves 9090, Cx. Postal 15094, Porto Alegre, RS 91540-000, Brazil. E-mail: moleta@terra.com.br

Five outbreaks of caprine enterotoxaemia in Rio Grande do Sul, Brazil, were studied. The animals were found dead or had a clinical course that usually lasted 2-3 hours. From two farms a clinical manifestation period of 12 hours was reported. Clinical signs were characterized by depression, marked abdominal discomfort, profuse watery diarrhea with fibrin clots, and death. Thirteen necropsies were performed and hydropericardium, hydrothorax and hydroperitoneum were commonly found. The mucosa and serosa of the colon were congested, and its contents was watery with multiple fibrin clots. Serosal hemorrhages and fibrin clots in the gallbladder were also seen. Fibrinous colitis and thyphilitis were the most frequent histological changes. Cerebral microangiopathy was observed in one case, which was characterized by acute perivascular proteinaceous edema around arterioles of the nucleus caudatus and thalamus. Large numbers of Gram-positive rods, often in clumps and with morphology consistent with Clostridium perfringens, were seen in intestinal smears. The intestinal contents of six goats were positive for epsilon toxin by mouse neutralization test. These findings suggest that enterotoxaemia is an important disease of goat flocks in southern Brazil.
\end{abstract}

INDEX TERMS: Goat enterotoxaemia, Clostridium perfringens, epsilon toxin.

SINOPSE.- São descritos surtos de enterotoxemia em caprinos em cinco propriedades no Estado do Rio Grande do Sul. Os animais afetados eram, normalmente, encontrados mortos ou apresentavam evolução aguda de $\mathbf{2}$ a 3 horas com acentu-

\footnotetext{
${ }^{1}$ Recebido em

Aceito para publicação em 5 de agosto de 2003.

${ }^{2}$ Departamento de Clinica Médica Veterinária, Universidade Federal de Mato Grosso (UFMT), Av. Fernando Correa da Costa s/n, Coxipó, Cuiabá, MT 78060600. E-mail: moleta@terra.com.br

${ }^{3}$ Departamento de Patologia Clínica Veterinária, UFRGS, Cx. Postal 15094, Porto Alegre, RS 91540-000.

${ }^{4}$ Laboratório Regional de Apoio Animal do Ministério da Agricultura, Pecuária e do Abastecimento (LARA), Rua Rômulo Joviano s/n, Pedro Leopoldo, MG 33600-000.

${ }^{5}$ Escola de Veterinária da UFMG, Av. Antônio Carlos 6627, Cx. Postal 567, Campus da UFMG, Belo Horizonte, MG 30123-970.

${ }^{6}$ California Animal Health and Food Safety Laboratory, San Bernardino, University of California, Davis.
}

ada depressão, cólicas abdominais e diarréia profusa com fibrina. Em duas propriedades relataram-se casos com a evolução de até 12 horas. Em treze animais necropsiados observaram-se aumento de líquidos nas cavidades abdominal, torácica e pericárdica, congestão e hiperemia da serosa e mucosa do intestino, conteúdo do cólon líquido com fibrina além de hemorragias de serosa e fibrina. Em um animal constatou-se microangiopatia cerebral caracterizada por acúmulo de material homogêneo e eosinofílico no espaço perivascular. No conteúdo intestinal, colônias com bastonetes morfológica e bioquimicamente sugestivos de Clostridium perfringens foram caracterizadas no estudo bacteriológico. A soroneutralização em camundongos com conteúdo intestinal dos animais afetados, revelou a presença da toxina épsilon. Estes achados evidenciam a enterotoxemia como doença de importância para criação de caprinos no Rio Grande do Sul.

TERMOS DE INDEXAÇÃO: Enterotoxemia caprina, Clostridium perfringens, toxina épsilon. 


\section{INTRODUÇÃO}

Enterotoxemia é o termo usado para descrever doenças causadas por toxinas produzidas no trato gastrintestinal, principalmente, por Clostridium perfringens (Buxton \& Donachie 1991). Os diferentes tipos de $C$. perfringens são classificados como A, B, C, D ou E em relação à variação na produção de quatro diferentes toxinas denominadas de principais (alfa, beta, épsilon e iota). As toxinas produzidas têm importância na patogenia das doenças associadas (Smart et al. 1979, McDonel 1980, Uzal \& Kelly 1998, Uzal et al. 2002). C. perfringens tipos B e D produzem uma protoxina que é ativada pela tripsina digestiva ou por toxinas secundárias de $C$. perfringens (Minami et al. 1997) formando a toxina épsilon associada com lesão no endotélio vascular (McDonel 1980). C. perfringens tipo $\mathrm{D}$ é a causa mais comum da enterotoxemia em ovinos e caprinos (McDonel 1980, Odendaal 1994, Uzal \& Kelly 1996, Van Metre et al. 2000). Fatores que alteram o ambiente intestinal, como níveis de elevados de carboidratos, dietas ricas em proteína e pastagens luxuriantes, podem permitir abundante crescimento de $C$. perfringens e produção de toxinas (Kriek et al. 1994, Smith \& Sherman 1994). A evolução de quadros clínicos de enterotoxemia em caprinos pode ser superaguda e, mais comumente, aguda ou crônica (Smith \& Sherman 1994, Uzal \& Kelly, 1996).

Microangiopatia cerebral, caracterizada por acúmulo perivascular de material eosinofilico proteináceo e hemorragias principalmente na cápsula interna, tálamo, pedúnculos cerebelares e cerebelo, caracteriza a enterotoxemia em ovinos sendo raramente encontrada em casos de enterotoxemia em caprinos (Buxton 1978, Uzal et al. 1997). Nesta espécie é mais freqüiente a ocorrência de lesões intestinais (Uzal \& Kelly 1996, Uzal et al. 1997).

A doença tem distribuição mundial (Roy \& Venkateswarlu 1969, Uzal et al. 1994, 1998a). No Brasil foi relatada a ocorrência de morte súbita por enterotoxemia em um rebanho caprino com base no estudo bacteriológico e de isolamento de uma toxina termolábil letal, que não foi caracterizada (Baldassi et al. 1995). Não há, no Brasil, relatos da ocorrência de enterotoxemia em caprinos com quadro de microangiopatia cerebral.

O objetivo deste trabalho é descrever os aspectos ambien- tais, clínicos, patológicos, toxicológicos e microbiológicos em diferentes surtos de enterotoxemia em caprinos no Estado do Rio Grande do Sul.

\section{MATERIAL E MÉTODOS}

Estudos epidemiológicos e quadro clínico

Os históricos clínicos da doença nos caprinos, que ocorreu de outubro de 2000 até outubro de 2002, foram obtidos junto aos proprietários e veterinários nas propriedades afetadas. São descritos cinco surtos em diferentes municípios do Estado do Rio Grande do Sul (Quadro 1).

\section{Estudo Patológico}

No Setor de Patologia Veterinária da Universidade Federal do Rio Grande do Sul (UFRGS) ou em propriedades afetadas, foram necropsiados 13 caprinos. Durante a necropsia fragmentos dos diferentes segmentos gástricos e intestinais, fígado, rim, pulmão, coração e o sistema nervoso central foram fixados em solução de formalina tamponada $10 \%$ e rotineiramente processadas para estudo histológico. Seções foram coradas com hematoxilina e eosina. Do encéfalo, para este estudo, foram analisados seç̧ões transversais do telencéfalo sobre o quiasma óptico, do diencéfalo sobre corpo mamilar, do mesencéfalo sobre os colículos caudais, do cerebelo sobre braço da ponte e da medula oblonga sobre o óbex. Coloração histológica com ácido periódico de Schiff (PAS) foi feita em cortes do sistema nervoso do caprino com lesões caracterizadas como microangiopatia cerebral.

\section{Isolamento bacteriano e caracterização bioquímica}

Conteúdo do íleo, ceco e cólon foi coletado durante a necropsia de dois caprinos do Surto 3 e de um caprino em cada um dos outros surtos. As amostras foram mantidas sob refrigeração e encaminhadas para Laboratório de Anaeróbios da Escola de Veterinária da Universidade Federal de Minas Gerais. Esfregaços do conteúdo intestinal dos animais afetados foram corados pela coloração de Gram. Amostras de conteúdo intestinal foram inoculadas em ágar sangue, em um meio seletivo para Clostridium perfringens (SPS-Difco, Maryland, USA) e em caldo Tioglicolato (Barcelona, Dignolab, Espanha) em anaerobiose a $37^{\circ} \mathrm{C}$ por 24 horas. Colônias isoladas foram submetidas a provas bioquímicas segundo Holt et al. (1994).

\section{Pesquisa de toxina por soroneutralização em camundongos}

Conforme técnica descrita por Sterne \& Batty (1975) com pequenas modificações, as amostras do conteúdo intestinal foram

Quadro 1. Aspectos epidemiológicos e evolução clínica de diferentes surtos de enterotoxemia por Clostridium perfringens tipo D em caprinos no Rio Grande do Sul

\begin{tabular}{|c|c|c|c|c|c|c|c|c|}
\hline \multirow[t]{2}{*}{ Surto } & \multirow[t]{2}{*}{ Município } & \multicolumn{3}{|c|}{ Animais afetados } & \multirow{2}{*}{$\begin{array}{l}\text { Animais no } \\
\text { rebanho }\end{array}$} & \multirow{2}{*}{ Evolução clínica } & \multirow{2}{*}{$\begin{array}{l}\text { Número de } \\
\text { necropsia }\end{array}$} & \multirow{2}{*}{$\begin{array}{l}\text { Coletas para } \\
\text { estudo bac- } \\
\text { teriológico }\end{array}$} \\
\hline & & Raça & $\begin{array}{l}\text { Idade } \\
\text { (meses) }\end{array}$ & Número & & & & \\
\hline 1 & Gravataí & $\begin{array}{c}\text { Saanen e } \\
\text { Anglo- Nubiana }\end{array}$ & $12-60$ & 57 & 130 & $\begin{array}{c}\text { Achados mortos } \\
\text { ou } 2-3 \text { horas }\end{array}$ & 6 & 1 \\
\hline 2 & Viamão & $\begin{array}{c}\text { Saanen e } \\
\text { Anglo- Nubiana }\end{array}$ & $8-30$ & 29 & 90 & $\begin{array}{c}\text { Achados mortos } \\
\text { ou } 3 \text { horas }\end{array}$ & 2 & 1 \\
\hline 3 & $\begin{array}{l}\text { Sta Maria } \\
\text { do Herval }\end{array}$ & Boer & $8-24$ & 6 & 120 & $\begin{array}{c}\text { Achados mortos } \\
\text { ou } 4-12 \text { horas }\end{array}$ & 3 & 2 \\
\hline 4 & Glorinha & Saanen & $12-36$ & 8 & 40 & $\begin{array}{c}\text { Achados mortos } \\
\text { ou } 4 \text { horas }\end{array}$ & 1 & 1 \\
\hline 5 & Gramado & Saanen & $12-24$ & 4 & 20 & 12 horas & 1 & 1 \\
\hline
\end{tabular}


centrifugadas a $10000 \mathrm{x} \mathrm{g} \mathrm{a} 4^{\circ} \mathrm{C}$ por 30 minutos e filtradas em filtro de $0,22 \mathrm{~mm}$. Do filtrado, uma alíquota de $0,2 \mathrm{ml}$ foi injetada em um grupo de camundongo. Em parte do filtrado, foi adicionada tripsina a $0,1 \%$ (Difco $1: 250$ ) e mantida a $37^{\circ} \mathrm{C}$ por 30 minutos, $0,2 \mathrm{ml}$ da amostra foi inoculada em outro grupo de camundongo. Filtrados com e sem adição de tripsina foram aquecidos a $100^{\circ} \mathrm{C}$ e $0,2 \mathrm{ml}$ de cada amostra, foi inoculado em diferentes grupos de camundongos. Filtrados adicionais com e sem tripsina foram misturados com igual parte de antitoxinas tipos alfa, beta e épsilon de $C$. perfringens, separadamente (NIBSC, Webridge, UK). Após 30 minutos de incubação a temperatura ambiente, $0,2 \mathrm{ml}$ de cada amostra foi inoculada em grupos distintos de camundongos. Todos os grupos, cada um composto por dois camundongos com 18 a 20 gramas, foram inoculados por via endovenosa e acompanhados por um período de 48 horas, registrando-se o número de mortos e vivos (Quadro 2).

Quadro 2. Procedimentos adotados para o conteúdo intestinal, na soroneutralização em camundongos, de caprinos com enterotoxemia e resultados obtidos

\begin{tabular}{cccccc}
\hline Grupo & Filtrado & Aquecido & Tripsina & Antitoxina & Resultado \\
\hline 1 & C & N & N & N & M \\
2 & C & C & N & N & V \\
3 & C & C & C & N & V \\
4 & C & N & C & Alfa & M \\
5 & C & N & C & Beta & M \\
6 & C & N & C & Épsilon & V \\
7 & C & N & N & Alfa & M \\
8 & C & N & N & Beta & M \\
9 & C & N & N & Épsilon & V
\end{tabular}

${ }^{\mathrm{a}} \mathrm{C}=$ Procedimento realizado, $\mathrm{N}=$ procedimento não realizado, $\mathrm{M}=$ morte, $\mathrm{V}=$ sem alterações clínicas.

\section{RESULTADOS}

Histórico e quadro clínico

Surto 1. Em uma propriedade no município de Gravataí, no período de janeiro até setembro de 2001 morreram 57 animais, de 1 a 5 anos de idade, de um total de 130 caprinos da raça Saanen e Anglo-Nubiana. Os animais eram confinados e alimentados com feno de alfafa e ração comercial (24\% proteína). Foram afetados principalmente os animais em ótimo estado corporal. Normalmente os animais eram encontrados mortos. Em alguns animais com evolução clínica de até três horas observou-se depressão, perda de apetite cólicas abdominais, diarréia aquosa com coloração verde-escura, por vezes com muco e fibrina. $O$ rebanho não era vacinado regularmente contra enterotoxemia. Foram necropsiados seis animais afetados em períodos que variaram de 1 a 10 horas após a morte.

Surto 2. Ocorreu no Município de Viamão onde em um rebanho confinado de 90 caprinos da raça Saanen e AngloNubiana, morreram 29 cabras, entre novilhas e adultas, no período de outubro de 2000 até novembro de 2001. Os animais eram alimentados com ração comercial e feno de alfafa. Normalmente, os animais eram encontrados mortos durante a manhã, não sendo observado sinais clínicos. Alguns animais apresentavam cólicas abdominais intensas, diarréia profusa e aquosa de coloração verde-escura ou avermelhada, tinham di- ficuldade respiratória e morriam com evolução de no máximo 3 horas. Dois animais, que receberam antimicrobianos no início do quadro clínico, recuperaram-se. O rebanho não era vacinado contra enterotoxemia. Dois animais foram necropsiados, um imediatamente e outro 5 horas após a morte.

Surto 3. Ocorreu no município de Santa Maria do Herval, em um rebanho com 120 caprinos da raça Bôer com idade entre 8 meses e 2 anos. Os animais eram mantidos em regime de semiconfinamento e recebiam ração concentrada com $20 \%$ de proteína. Na maioria dos casos os animais foram encontrados mortos. Alguns foram observados com depressão, anorexia, dores abdominais e diarréia líquida profusa com evolução de 4 a 12 horas. Animais que adoeceram e foram medicados no início do quadro recuperaram-se. Seis animais morreram no mês de setembro de 2002. A última vacinação para enterotoxemia tinha ocorrido um ano antes da mortalidade. Três animais deste surto foram necropsiados aproximadamente 8 horas após a morte.

Surto 4. Nesta propriedade, no município de Glorinha, oito de um total de quarenta caprinos da raça Saanen, com idade entre 1 e 3 anos, morreram com quadro clínico semelhante. Normalmente eram encontrados mortos ao amanhecer. Alguns sinais clínicos observados caracterizaram-se por gemidos, contrações da musculatura abdominal, diarréia líquida e profusa com evolução de aproximadamente 4 horas. A recuperação clínica de animais após o tratamento com antimicrobiano foi rara. $O$ rebanho recebia ração com $22 \%$ de proteína, silagem de milho e alfafa. Os animais foram vacinados contra enterotoxemia quatro meses antes do início das mortes. Um animal foi necropsiado 4 horas após a morte.

Surto 5. No município de Gramado, morreram quatro animais, com idade entre 12 anos, de um total de 20, todos adquiridos há 20 dias na propriedade do Surto 4 . 0 rebanho era alimentado com feno de alfafa ração comercial com $22 \%$ de proteína e silagem de milho. As mortes começaram uma semana após o transporte. Os animais apresentavam diarréia profusa e morte no máximo em 12 horas. Os animais foram vacinados contra enterotoxemia quatro meses antes do início das mortes. Um animal foi necropsiado aproximadamente 5 horas após a morte.

\section{Achados patológicos}

Todos os animais necropsiados apresentavam bom estado corporal e alterações similares com diferenças em severidade. As principais lesões observadas foram no colon e ceco que apresentavam serosa intensamente avermelhada, por vezes com edema mural. O conteúdo era líquido com coloração verde-escuro ou avermelhado, contendo filamentos de fibrina (Fig. 1). Membranas amareladas recobriam segmentos da mucosa do intestino principalmente no ceco e cólon. Os linfonodos mesentéricos estavam com volume aumentado. Foi encontrado, com frequiência, líquido nas cavidades abdominal, torácica e pericárdica, por vezes com filamentos de fibrina. Os rins estavam congestos e na maioria dos animais, necropsiados 3 horas 


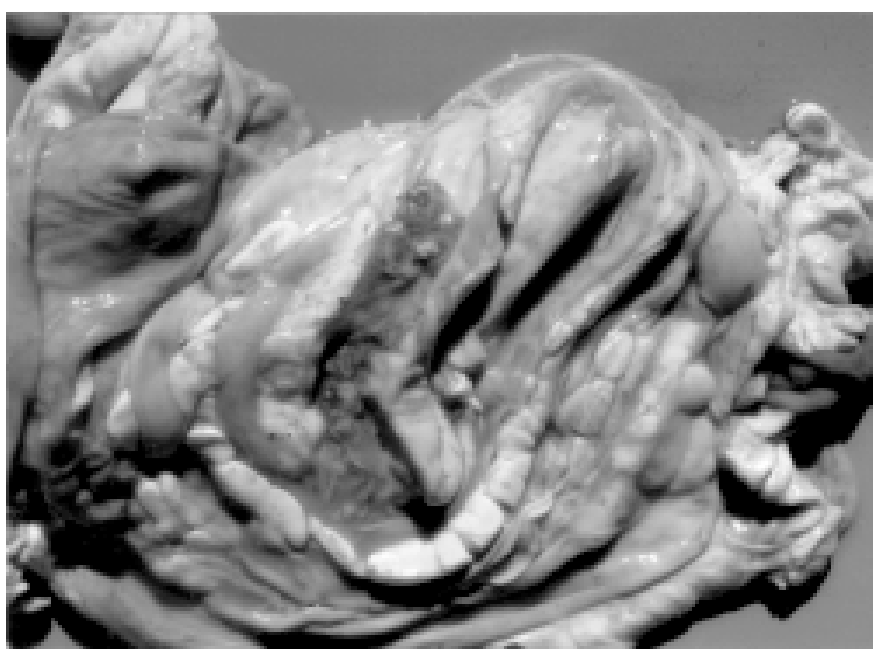

Fig. 1. Colon espiral com conteúdo líquido e fibrina, na enterotoxemia de caprino.

após a morte, a cortical renal estava amolecida. Edema e congestão pulmonar, fígado congesto com vesícula biliar espessa e repleta por conteúdo líquido, com grumos de fibrina, foram achados freqüentes. Observaram-se também petéquias e equimoses, especialmente, no peritônio, pleura, epicárdio, endocárdio, diafragma, timo, rins e pâncreas.

No estudo histológico, principalmente no ceco e cólon, as alterações variaram de congestão e hemorragia leve à inflamação fibrinosa com intensa quantidade de células epiteliais descamadas e grande quantidade de bactérias bacilares basofilicas na luz intestinal. Notaram-se, também, restos celulares principalmente de polimorfonucleares, nas glândulas intestinais e edema da submucosa. Nos rins dos caprinos que tinham a região cortical amolecida, apresentavam graus variados de autólise caracterizada por células epiteliais dos túbulos contorcidos proximais com citoplasma tumefeito, eosinofílico e com núcleo ausente ou fragmentado e aumento de material

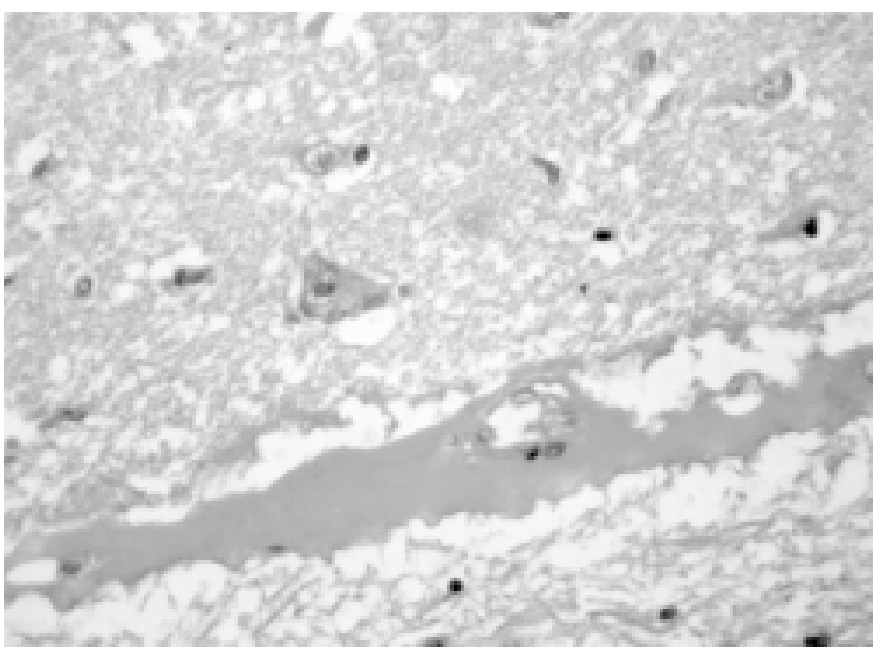

Fig. 2. Acúmulo de material proteináceo hialino, ao corte transversal do encéfalo sobre o núcleo caudato, de caprino com enterotoxemia. HE, obj. 40. eosinofílico na luz tubular. Em um dos animais do Surto 1, foi constatado no núcleo caudato e tálamo dorsal, principalmente em arteríolas, acúmulo de material eosinofílico hialino no espaço perivascular (Fig. 2), PAS positivo e leve eosinofilia da túnica média e discreta tumefação do endotélio.

\section{Estudo microbiológico}

Grande quantidade de bastonetes curtos, grossos, não esporulados Gram positivos únicos ou em cadeias, foram observados a partir dos esfregaços da mucosa intestinal. Colônias acinzentadas, umbilicadas com um duplo halo de hemólise de aproximadamente de $2 \mathrm{~mm}$ de diâmetro sugestivas de Clostridium perfringens foram observadas nas placas de ágar sangue. Colônias enegrecidas acinzentadas cresceram no meio seletivo para $C$. perfringens. No caldo tioglicolato sub-cultivado anaerobicamente em ágar sangue notou-se profuso crescimento de cultura pura de colônias idênticas àquelas isoladas diretamente no ágar sangue. Pela caracterização bioquímica, as colônias isoladas foram confirmadas tratar-se de $C$. perfringens.

\section{Soroneutralização em camundongos}

No teste de soroneutralização em camungondos, todos os animais inoculados com filtrado de toxina inicial (sem a adição das antitoxinas) morreram num período inferior a 24 horas. Quando a toxina foi aquecida a $100^{\circ} \mathrm{C}$ os camundongos não apresentaram alterações. Após tratamento com as antitoxinas, tanto em filtrado com tripsina como sem tripsina, morreram os inoculados com as antitoxinas alfa e beta e não morreram os dois camundongos inoculados com anti-épsilon.

\section{DISCUSSÃO}

A morte dos seis caprinos com estudo patológico, bacteriológico e soroneutralização em camundongos foram atribuídas à produção da toxina épsilon por Clostridium perfringens. Acredita-se, com base no histórico clínico e achados patológicos que enterotoxemia tenha sido a causa da mortalidade de caprinos nos diferentes surtos estudados. Evidências adicionais de que enterotoxemia era a causa da doença incluem a diminuição ou cessação das mortes após a vacinação e alterações, na dieta, dos níveis de proteína e carboidrato na ração.

C. perfringens não é abundante, mas normalmente habita a flora digestiva de ruminantes saudáveis (Willis 1969, Niilo 1980, Van Metre et al. 2000). Sabe-se, também que animais não vacinados toleram níveis baixos de toxina épsilon sem que ocorra quadro clínico (Bullen 1970, Uzal et al. 2002), portanto, o diagnóstico de casos suspeitos de enterotoxemia, deve estar baseado nos achados epidemiológicos, clínicos, patológicos, microbiológicos e caracterização de toxinas específicas (Uzal et al. 2003).

A toxina épsilon é produzida por C. perfringens tipos B e D (Niilo 1980, Odendaal 1994). Neste estudo, na prova de soroneutralização, filtrados adicionados com antitoxinas alfa e beta mataram os camundongos. Não foram afetados os camundongos inoculados com antitoxina épsilon, indicando que a toxina beta que caracteriza $C$. perfringens tipo $B$ não estava presente. A ativação da protoxina épsilon por toxinas secun- 
dárias de $C$. perfringens, como a toxina lambda (Minami et al. 1997), pode explicar a morte do grupo de camundongos no qual foi inoculado filtrado intestinal sem tripsina.

A toxina épsilon é a principal responsável pelo quadro clínico e lesões da enterotoxemia em caprinos (Niilo 1980, McDonel 1980). Fatores que predispõem a enterotoxemia, como trocas súbitas de alimentos e níveis altos de carboidratos e proteínas, podem levar a intensa multiplicação de $C$. perfringens no intestino e produção de toxina (Kriek et al. 1994, Smith \& Sherman 1994). A toxina absorvida na luz intestinal causa aumento da permeabilidade vascular ocorrendo aumento dos líquidos cavitários com deposição de fibrina e edema pulmonar (Gardner 1973).

A microangiopatia cerebral caracteristicamente associada com $C$. perfringens tipo $\mathrm{D}$, tem sido observada com freqüência em casos de enterotoxemia de ovinos e é pouco descrita em caprinos (Uzal et al. 1997). A baixa incidência e a patogenia da microangiopatia cerebral em caprinos não foi, ainda, esclarecida (Blackwell et al. 1991, Blackwell \& Butter 1992, Uzal et al. 1997). Possivelmente a atividade de toxinas produzidas por $C$. perfringens na mucosa intestinal tenha importância no desenvolvimento das lesões (Barker et al. 1993). Acredita-se que absorção da toxina épsilon seja maior e mais rápida no intestino de ovinos ocorrendo lesões sistêmicas nesta espécie. Em caprinos normalmente é menor a absorção de toxinas no intestino delgado, sendo mais evidente a enterocolite (Blackwell et al. 1991, Buxton \& Morgan 1976, Finnie et al. 1999).

Caprinos são considerados sensíveis à enterotoxemia recomendando-se a vacinação para prevenção (Smith \& Sherman 1994). Caprinos vacinados com vacinas comerciais polivalentes contra enterotoxemia têm títulos de antitoxinas menores e menos duráveis que os observados em ovinos (Green et al. 1987, Uzal et al. 1998b). Em caprinos ocorrerem variações individuais na resposta à imunização, aos intervalos de vacinação (Blackwell et al. 1983, Green et al.1987) e aos adjuvantes (Uzal et al. 1998b). Preconiza-se para manter níveis altos de proteção vacinar rebanhos susceptíveis de 3 a 4 vezes por ano. As fêmeas gestantes devem ser vacinadas 2 a 3 semanas antes do parto e os filhotes com 4 meses de idade (Smith \& Sherman 1994). Durante surtos de enterotoxemia recomenda-se revacinação entre 15 e 30 dias após a primeira dose. Também são recomendadas, junto com a imunização, alterações do manejo alimentar, especialmente diminuição do nível de proteína e carboidratos (Smith \& Sherman 1994, Uzal \&Kelly 1996).

\section{REFERÊNCIAS}

Baldassi L., Calil E.M.B., Portugal M.A.S.C., Moulin A.A.P. \& Mourão M.A.F. 1995. Morte súbita de caprinos por enterotoxemia. Braz. J. Vet. Anim. Sci. 32(2):109-113.

Barker I.K., Van Dreumel A.A. \& Palmer N. 1993. The alimentary system, p. 237-247. In. Jubb K.V.F., Kennedy P.C. \& Palmer N. (ed.) Pathology of Domestic Animals. Vol. 2. 4th ed. Academic Press, San Diego.

Blackwell T.E. \& Butler D.G. 1992. Clinical signs, treatment and post-mortem lesions in dairy goats with enterotoxaemia: 13 cases (1979-1982). J. Am. Vet. Med. Assoc. 200:214-217.
Blackwell T.E., Butler D.G. \& Bell J.A. 1983. Enterotoxaemia in the goat: The humoral response and local tissue reaction following vaccination with two different bacterin-toxoids. Can. J. Comp. Path. Med. 47:127-132.

Blackwell T.E., Butter D.G., Prescott J.F. \& Wilcock B.P. 1991. Differences in signs and lesions in sheep and goats with enterotoxemia induced by intraduodenal infusion of Clostridium perfringens type D. Am. J. Vet. Res. 52 (7):1147-1152.

Bullen J.J. 1970. Role of toxins in host-parasite relationships, p. 223-276. In: Kadis S., Montie T.C. \& Ajl S.J. (ed.) Microbial Toxins. Vol. 2. Academic Press, London.

Buxton D. \& Donachie, W. 1991. Clostridial diseases, p. 104-114. In: Martin W.B. \& Aitken I.D. (ed.) Diseases of Sheep. 2nd ed. Blackwell Scientific Publications, Oxford

Buxton D. 1978. Further studies on the mode of action of Clostridium welchii type D epsilon toxin. J. Medical Microb. 11:293-298.

Buxton D. \& Morgan K.T. 1976. Studies of lesions produced in the brains of colostrums-deprived lambs by Clostridium welchii (C. perfringens) type D toxin. J. Comp. Path. 86:435-447.

Finnie J.W., Blumbergs P.C. \& Manavis J. 1999. Neuronal damage produced in rat brains by Clostridium perfringens type D epsilon toxin. J. Comp. Path. 120:415-420.

Gardner D.E. 1973. Pathology of Clostridium welchii type D enterotoxemia. II. Structural and ultrastrutural alterations in the tissues of lambs and mice. J. Comp. Path. 83:525-529.

Green D.S., Green M.J., Hilyer M.H. \& Morgan, K.L. 1987. Injection site reactions and antibody responses in sheep and goats after the use of a multivalent clostridial vaccine. Vet. Rec. 120:435-439.

Holt J.G., Krieg N.R., Sneath P.H.A., Staley J.T.b \& Williams S.T. 1994. Bergey's Manual of Determinative Bacteriology. 9th ed. Williams \& Wilkins, Baltimore, p.749-755.

Kriek N.P.J., Odendaal M.W. \& Hunter P. 1994. Clostridium perfringens type D enterotoxaemia, p. 1315-1322. In: Coetzer J.A.W., Thomson G.R. \& Tustin R.C. (ed.) Infectious Diseases of Livestock with special reference to Southern Africa. Vol. 2. Oxford University, Oxford.

McDonel J.L. 1980. Clostridium perfringens (type A, B, C, D, E). Pharmacol. Ther. 10 (3):617-655.

Minami J., Katayama S., Matsushita O., Matsushita C. \& Okabe A. 1997. Lambdatoxin of Clostridium perfringens activates the precursor of epsilon-toxin by releasing its $\mathrm{N}$ - and C-terminal peptides. Microbiol. Immunol. 41(7):52735.

Niilo L. 1980. Clostridium perfringens in animal disease: A review of current knowledge. Can. Vet. J. 21:141-148.

Odendaal M.W. 1994. Clostridium perfringens group, p. 1290-1298. In: Coetzer J.A.W., Thomson G.R. \& Tustin R.C. (ed.) Infectious Diseases of Livestock with special reference to Southern Africa. Vol. 2. Oxford University, Oxford.

Roy K.S.R.R.M. \& Venkateswarlu K. 1969. Incidence of infectious enterotoxaemia in goats in Andhra Pradesh. Indian Vet. J. 6:806-807.

Smith M.C \& Sherman D.M. 1994. Digestive System, p. 298-302. In: Goat Medicine. Lea \& Febiger, Philadelphia.

Smart J.L., Roberts T.A., Stringer M.F. \& Shah N. 1979. The incidence and serotypes of Clostridium perfringens on beef, pork and lamb carcasses. J. Appl. Bact. 46:377-383.

Sterne M. \& Batty I. 1975. Pathogenic Clostridia. Butterworth, London, p. 7895.

Uzal F.A. \& Kelly W.R. 1996. Enterotoxaemia in goats: A review. Vet. Res. Commun. 20:481-492.

Uzal F.A. \& Kelly W.L. 1998. Experimental Clostridium perfingens type D enterotoxemia in goats. Vet. Pathol. 35:132-140.

Uzal F.A., Pasini M.I., Olaechea F.V., Robles C.A. \& Elizondo A. 1994. An outbreak of enterotoxaemia caused by Clostridium perfringens in goats in Patagonia. Vet. Rec.135:279-280.

Uzal F.A., Glastonbury J.R.W., Kelly, W.R. \& Thomas R. 1997. Caprine enterotoxaemia associated with cerebral microangiopathy. Vet. Rec. 141:224-226. 
Uzal F.A., Kelly W.R. \& Parsons P.G. 1998a. Enterotoxaemia in goats in Australia. Aust. Vet. J. 76(8):543.

Uzal F.A., Bodero D.A., Kelly W.R. \& Nielsen K. 1998b. Variability of serum antibody responses of goat kids to a commercial Clostridium perfingens epsilon toxoid vaccine. Vet Rec. 143(17):472-474.

Uzal F.A., Kelly, W.R, Morris W.E. \& Assis RA. 2002. Effects of intravenous injection of Clostridium perfringens type D epsilon toxin in calves. J. Comp. Path. 126:71-75.
Uzal F.A., Kelly W.R., Thomas R., Hornitzky M. \& Galea F. 2003. Comparison of four techniques for the detection of Clostridium perfringens type $\mathrm{D}$ epsilon toxin in intestinal contents and other body fluids of sheep and goats. J. Vet. Diagn. Invest. 15(2):94-99.

Van Metre D.C., Tyler J.W. \& Stehman S.M. 2000. Diagnosis of enteric disease in small ruminants. Vet. Clin. North Am. Food. Anim. Pract. 16(1):87-115.

Willis T.A. 1969. Clostridia of Wound Infection. Butterworth, London. 490p. 